\title{
Surface deformation due to a strike-slip fault in an elastic gravitational layer overlying a viscoelastic gravitational half-space
}

\author{
Ting-To Yu ${ }^{1}$ and John B. Rundle \\ Cooperative Institute for Research in Environmental Sciences, University of Colorado, Boulder \\ Jose Fernández \\ Instituto de Astronomia y Geodesia, Facultad de Ciencias Matematicas, Ciudad Universitaria, Madrid, Spain
}

\begin{abstract}
We extend a technique previously used to model surface displacements resulting from thrust faulting in an elastic-gravitational layer over a viscoelastic-gravitational half-space to the case of strike-slip faulting. The method involves the calculation of the Green's functions for a strike-slip point source contained in an elastic-gravitational layer over a viscoelastic-gravitational half-space. The correspondence principle of linear viscoelasticity is applied to introduce time dependence. The resulting Green's functions are then integrated over the source region to obtain the near-field displacements. Several sample calculations are presented involving $90^{\circ}$ and $30^{\circ}$ dipping faults and ruptures completely and partially through the elastic layer. We also illustrate the time dependent deformation due to a buried fault. Results show that the use of a viscoelastic half-space underlying an elastic layer introduces a long wavelength component into the deformation field [Cohen and Kramer, 1984], even in cases of non vertical strike-slip fault and inclusion of gravitational effect, that cannot be modeled by purely elastic techniques. Calculations have shown that vertical postseismic displacement is insignificant and that the horizontal movement is about the same magnitude as the coseismic strike-slip displacement. The inclusion of gravity affects the horizontal displacement due to vertical strike-slip faulting in far field and the vertical displacement for dipping strike-slip faulting in near-field. The computed results have been fit to the Global Positioning System measurements of the Landers earthquake taken shortly after the main shock, assuming a relaxation time of the order of days. This relaxation time is considerably shorter than times of the order of years to decades found in previous studies. The major differences between this detailed three-dimensional and simplified two-dimensional model are the decay of magnitude in displacement field and the distinct displacement pattern in the regions beyond the fault tip. The displacement field due to the cyclic earthquakes was constructed by considering the finite fault length and inclusion of gravity. It is found that the displacement field is dominated by the plate motion in the case of short recurrence time. On the other hand, a "looping" and migrating pattern in the displacement field is found in the case of very long recurrence time, which is not seen in those 2D simplified models.
\end{abstract}

\section{Introduction}

An important goal of modern crustal deformation studies is to understand the transient post event ground deformation sometimes seen following large earthquakes. Measurements of surface displacements reveal the presence of transient strain patterns in the crust after such events. Stress relaxation in a non elastic region situated below the surface elastic zone is believed to be one of the driving mechanisms of transient strain [Nur and Mavko, 1974]. A second possible explanation is continued slip at depth on the fault [Fitch and Scholz, 1971]. The postseismic displacements can be explained by either of these two mechanisms using certain assumptions. By inverting the geodetic data and comparing the assumptions to the geology or seismicity

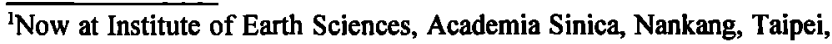
Taiwan.

Copyright 1996 by the American Geophysical Union.

Paper number 95JB03118.

0148-0227/96/95JB-03118\$05.00 constraints, analytical models can be used to provide a means of distinguishing between these mechanisms.

Elastic models involving dislocation sources in a homogeneous half-space [e.g., Chinnery, 1961] or in a layered half-space [e.g., Jovanovich et al., 1974] cannot explain transient deformations following an earthquake. Time dependence can be introduced by including viscoelastic relaxation or time dependent slip. Such models have been studied by Nur and Mavko [1974], Spence and Turcotte [1979], Savage and Prescott [1978], and Matsu'ura and Tanimoto [1980] among others. Rundle and Jackson [1977] used an analytic approximation of the Green's function to calculate displacements due to a strike-slip point source in an elastic layer over a viscoelastic half-space. Cohen and Kramer [1984], Li and Rice [1987], Lehner and $L i$ [1982], and Spence and Turcotte [1979], used two-dimensional model with various approaches to study the displacement field or cyclic deformations due to infinite long vertical strike-slip faults. Yang and Toksöz [1981] studied the time dependent deformations due to finite vertical strike-slip faults with three-dimensional finite element method. They reported the significant effects in the region beyond the fault tip 
which cannot be found in a simplified 2D model. Rundle [1978, 1980] used the exact Green's functions for finite quasi-static sources in an elastic layer over a linear viscoelastic half-space to calculate the viscoelastic crustal deformation for a thrust fault. Hofton et al. [1995] studied the surface deformation due to dike emplacement by exact calculation of viscoelastic-gravitational Green's functions. Ma and Kusznir [1992, 1993, 1994] calculated displacements for a fully relaxed model by setting the elastic Láme parameters equal to their relaxed values. However, they neither calculated deformation during transient relaxation nor did they show the viscoelastic behavior. Pollitz [1992] modeled the effects of postseismic relaxation on a spherical symmetric Earth with the normal mode formalism.

We extend the work of Rundle $[1980,1981]$ to include the case of strike-slip faulting in an elastic- gravitational layer overlying a viscoelastic-gravitational half-space. The viscoelastic region must possess instantaneous elastic properties. We also assume small perturbation strains which imply that materials in the viscoelastic region obey linear-constitutive laws. Furthermore, a Maxwell rheology is assumed, which implies that the viscoelastic region behaves as an elastic solid over short time periods and as a Newtonian fluid over long timescales.

We include gravitational effects in our calculations. For deformation at the surface of an elastic half-space, gravitational effects become significant over wavelengths greater than $1000 \mathrm{~km}$ [Rundle, 1980] but has little relevance to the near-field deformation for a vertical strike-slip fault because vertical displacements are insignificant. In viscoelastic models, stresses in some regions of Earth decrease as flow occurs: the initial elastic stresses induce flow in the medium, generating a change in the displacements and gravitational stresses as a result. Equilibrium is eventually attained between the gravitational and elastic stresses in the flowing region. However, for a vertical strike-slip fault, gravitational effects are insignificant in the near-field, and the inclusion of gravitational effects is important only in cases of non vertical dip angle.

In this paper, surface displacements following a dipping strike-slip faulting are modeled using Green's functions. The solutions for the elastic-gravitational problem are computed, then the correspondence principle, which relates the elasticgravitational solution to the Laplace-transformed viscoelasticgravitational solution, is applied. Finally, the Green's functions are integrated over the finite source region to obtain the time dependent, near-field displacements.

To show an example of using our model, a comparison between calculated results and the Global Positioning System (GPS) measurements of the Landers earthquake is made. The magnitude and decay pattern of survived data fit the result derived from this model, although the relaxation times obtained are considerably shorter than those found in previous studies of viscoelastic rebound [e.g., Thatcher and Rundle, 1984]. However, Shen et al. [1994] do find the same relaxation period in all the GPS baselines measured shortly after the Landers earthquake. The difference in these two findings may be caused by various relaxation mechanisms in diverse regions.

\section{Solution to the Infinite Space Problem}

The equations to be solved [Love, 1911] are:

$$
\begin{gathered}
\nabla^{2} \mathrm{u}+\frac{1}{1-2 \sigma} \nabla \nabla \cdot \mathrm{u}+\frac{\rho_{0} \mathrm{~g}}{\mu} \nabla\left(\mathrm{u} \cdot \mathrm{e}_{\mathrm{z}}\right)-\frac{\rho_{0}}{\mu} \nabla \phi-\frac{\rho_{0} \mathrm{~g}}{\mu} \mathrm{e}_{\mathrm{z}} \nabla \cdot \mathrm{u}=0 \\
\nabla^{2} \phi=-4 \pi \rho_{0} \mathrm{G}_{0} \nabla \cdot u
\end{gathered}
$$

where $u$ is the perturbed displacement vector in the deformed cylindrical coordinate system $(r, \theta, z), \phi$ is the gravitational potential in this coordinate system, $e_{r}, e_{\theta}$ and $e_{z}$ are the unit vectors, $\sigma$ is Poison's ratio, $\rho_{0}$ is the density, and $\mu$ is the rigidity.

Rundle [1981] found that for displacements resulting from a dip-slip event in a layered elastic-gravitational medium, selfgravitation effects arising from the nonzero values of $G_{0}$, the gravitational constant, were generally much smaller than gravitational effects relating to the surface acceleration $g$. As $z$ $\rightarrow \pm \infty$, all perturbed quantities are presumed to tend to zero, so setting $G_{0}=0$ implies $\phi$ is constant. Making use of this, Rundle [1981] used the equation

$$
\nabla^{2} u+\frac{1}{1-2 \sigma} \nabla \nabla \cdot u+\frac{\rho_{0} g}{\mu} \nabla\left(u \cdot e_{z}\right)-\frac{\rho_{0} g}{\mu} e_{z} \nabla \cdot u=0 .
$$

Using the vector base,

$$
\begin{gathered}
\boldsymbol{P}_{\mathrm{m}}=e_{\mathrm{r}} \mathrm{J}_{\mathrm{m}}(\mathrm{kr}) \exp (\mathrm{im} \theta) \\
\boldsymbol{B}_{\mathrm{m}}=\left(\frac{\partial}{\partial \mathrm{kr}} e_{\mathrm{r}}+e_{\theta} \frac{1}{\mathrm{kr}} \frac{\partial}{\partial \theta}\right) \mathrm{j}_{\mathrm{m}}(\mathrm{kr}) \exp (\mathrm{im} \theta) \\
\boldsymbol{C}_{\mathrm{m}}=\left(\frac{1}{\mathrm{kr}} \frac{\partial}{\partial \theta} e_{\mathrm{r}}-e_{\theta} \frac{\partial}{\partial \mathrm{kr}}\right) \mathrm{j}_{\mathrm{m}}(\mathrm{kr}) \exp (\mathrm{im} \theta)
\end{gathered}
$$

where $J_{m}(k r)$ are cylindrical Bessel functions, $i=\sqrt{-1}$ and $k$ corresponds to the wave number in dynamic problems [BenMenahem and Singh, 1968], we can expand $u$ in (4a) $-(4 c)$ :

$$
\boldsymbol{u}=\sum_{m=0}^{\infty} \int_{0}^{\infty} k d k\left[\mathrm{~W}_{m}(z) \boldsymbol{P}_{m}+\mathrm{U}_{m}(\mathrm{z}) \boldsymbol{B}_{\mathrm{m}}+\mathrm{v}_{\mathrm{m}}(\mathrm{z}) \boldsymbol{C}_{\mathrm{m}}\right]
$$

The solution given by $V_{m}(z)$ is not considered further here as it is identical to the solution in the nongravitating case. $U_{m}(z)$ and $W_{m}(z)$ are given by Rundle [1981]:

$$
\left(\begin{array}{c}
U_{m}(z) \\
W_{m}(z)
\end{array}\right)=\left(\begin{array}{c}
1 \\
p_{1}^{+}(k)
\end{array}\right) e^{a_{1} z}+\left(\begin{array}{c}
1 \\
p_{1}^{-}(k)
\end{array}\right) e^{-a_{1} z}+k\left(\begin{array}{c}
1 \\
p_{2}^{+}(k)
\end{array}\right) e^{a_{2} z}+k\left(\begin{array}{c}
1 \\
p_{2}^{-}(k)
\end{array}\right) e^{-a_{2} z}
$$

where

$$
\begin{gathered}
\pm \mathrm{a}_{1}= \pm\left(\mathrm{k}^{2}+\mathrm{k} \eta \sqrt{\zeta}\right)^{1 / 2} \\
\pm \mathrm{a}_{2}= \pm\left(\mathrm{k}^{2}-\mathrm{k} \eta \sqrt{\zeta}\right)^{1 / 2} \\
\zeta=\frac{1-2 \sigma}{2(1-\sigma)}, \quad \eta=\frac{\rho_{0} g}{\mu} \\
\mathrm{p}_{\mathrm{j}}^{ \pm}(\mathrm{k})= \pm 1-\frac{\mathrm{k} \eta \sqrt{\zeta}}{\left(\mathrm{a}_{\mathrm{j}}+\mathrm{k}\right)} \frac{1+\sqrt{\zeta}}{\mathrm{a}_{\mathrm{j}}-\mathrm{k} \sqrt{\zeta}}
\end{gathered}
$$

where, $j=1,2$. The gravitational wave number $k_{g}$ found by setting $a_{2}(k)=0$ is defined as

$$
\mathrm{k}_{\mathrm{g}}=\eta \sqrt{\zeta}
$$

For $k<k_{g}, a_{2}$ is purely imaginary, and for $k>k_{g}, a_{2}$ is real. 


\section{Solution to the Layered Half-Space Problem}

Rundle [1980] used a polar coordinate system $(r, \theta, z)$ and the $z$ axis oriented down into the medium at the surface of a layered, elastic-gravitational half-space. The elastic module in the $n$th layer are denoted by $\lambda_{n}$ and $\mu_{n}$ and the density by $\rho_{n}$ The solution in the $n$th layer is given by

$$
u^{n}=\sum_{m=0}^{\infty} \int_{0}^{\infty} k d k u m
$$

where $u^{n} m$ is given by

$$
u_{m}^{n}=x_{m}^{n} P_{m}+y_{m}^{n} B_{m}+z_{m}^{n} C_{m} .
$$

The kernel functions $x_{m}^{n}, y_{m}^{n}, z_{m}^{n}$ are

$$
\begin{aligned}
& x_{m}^{n}=-e^{-k z} A_{m n}^{-}+e^{k z} A_{m n}^{+}+p_{1}^{-} e^{-a_{1} z} B_{m n}^{-} \\
& +p_{1}^{+} e^{a_{1} z} B_{m n}^{+}+k p_{2} e^{-a z_{2} z} D_{m n}^{-}+k p_{2}^{+} e^{a_{2} z} D_{m n}^{+} \\
& y_{m}^{n}=e^{-k z} A_{m n}^{-}+e^{k z} A_{m n}^{+}+e^{-a_{1} z} B_{m n}^{-}+e^{a_{1} z} B_{m n}^{+} \\
& +k e^{-a} 2^{z} D_{m n}^{-}+k e^{a} 2^{z} D_{m n}^{+} \\
& z_{m}^{n}=e^{-k z} C_{m n}^{-}+e^{k z} C_{m n}^{+} .
\end{aligned}
$$

The same formulation is applied to the stresses across the layer boundaries to obtain similar expressions for the normal tractions across a plane.

As can be seen from (11a) - (11c), the problem can be divided into two separate parts, the "R" problem (that includes the $x^{n} m$ and $y^{n} m$ terms) and the "L" problem (that includes the $z^{n}{ }_{m}$ terms). The solutions to these problems are given by Rundle [1980 equations 88-96].

\section{Source Functions}

The source functions $D_{m}$ for the six elementary displacement dislocation sources have been derived by Ben-Menahem and Singh [1968]. In the notation of Singh [1970], $(j k)$ refer both to the direction of the force system and the normal to the plane across which it is applied. For a fault plane inclined at an angle $\Psi$ to the horizontal

$$
(j k)=(1,2) \cos \psi+(3,1) \sin \psi
$$

with each component given by

$$
\begin{array}{lll}
(j k)=(1,2) & \left(D_{2}\right)_{4}=\mu \gamma \mathrm{i} & \left(D_{2}^{\mathrm{L}}\right)_{2}=2 \mu \gamma \\
(j k)=(3,1) & \left(D_{1}\right)_{2}=2 \gamma \quad\left(D_{1}^{L}\right)_{1}=-2 \gamma \mathrm{i} .
\end{array}
$$

Here $\gamma=\Delta U d \Sigma / 4 \pi, \Delta U$ is the relative displacement across the fault plane, and $d \Sigma$ is an element of area on the fault.

Hence we have two different source function contributions to the strike-slip problem, both describing a shearing component $(m=1,2)$. Using (9) and (10) and summing these two contributions, the displacement at the surface may be written

$$
\begin{aligned}
u=\int_{0}^{\infty} k d k\left\{\left[x_{2}^{1}(0) P_{2}+y_{2}^{1}(0) B_{2}+z_{2}^{1}(0) C_{2}\right] \cos \psi\right. \\
\left.+\left[x_{1}^{1}(0) P_{1}+y_{1}^{1}(0) B_{1}+z_{1}^{1}(0) C_{1}\right] \sin \psi\right\}
\end{aligned}
$$

Substituting (4a)-(4c) for $P_{m}, B_{m}$, and $C_{m}$, replacing $e^{i m^{\theta}}$ and $i e^{i m^{\theta}}$ by $\cos m \theta$ and $-\sin m \theta$, respectively, to obtain the real part and splitting the displacement vector into its three components, we obtain

$$
\begin{aligned}
\mathrm{u}_{\mathrm{r}}= & \int_{0}^{\infty} \mathrm{kdk}\left\{\left[\frac{1}{1} \mathrm{y}_{1}^{1}(0)\left(\frac{\partial}{\partial \mathrm{kr}}\right) \mathrm{J}_{1}(\mathrm{kr})+\mathrm{z}_{1}^{1}(0)\left(\frac{1}{\mathrm{kr}}\right) \mathrm{J}_{1}(\mathrm{kr})\right] \cos \theta \cos \psi\right. \\
& \quad-\left[\mathrm{y}_{2}^{1}(0)\left(\frac{\partial}{\partial \mathrm{kr}}\right) \mathrm{J}_{2}(\mathrm{kr})+\frac{1}{\mathrm{i}} \mathrm{z}_{2}^{1}(0)\left(\frac{1}{\mathrm{kr}}\right) \mathrm{J}_{2}(\mathrm{kr}) \sin 2 \theta \sin \psi\right\} \\
\mathrm{u}_{\theta}= & -\int_{0}^{\infty} \mathrm{kdk}\left\{\left[\frac{1}{1} \mathrm{y}_{1}^{1}(0)\left(\frac{1}{\mathrm{kr}}\right) \mathrm{J}_{1}(\mathrm{kr})+\mathrm{z}_{1}^{1}(0)\left(\frac{\partial}{\partial \mathrm{kr}}\right) \mathrm{J}_{1}(\mathrm{kr})\right] \sin \theta \cos \psi\right. \\
+ & {\left.\left[\mathrm{y}_{2}^{1}(0)\left(\frac{2}{\mathrm{kr}}\right) \mathrm{J}_{2}(\mathrm{kr})+\frac{1}{\mathrm{i}} \mathrm{z}_{2}^{1}(0)\left(\frac{\partial}{\partial \mathrm{kr}}\right) \mathrm{J}_{2}(\mathrm{kr})\right] \cos 2 \theta \sin \psi\right\} } \\
\mathrm{u}_{\mathrm{z}}= & -\int_{0}^{\infty} \mathrm{kdk}\left\{\frac{1}{1} \mathrm{x}_{1}^{1}(0) \mathrm{J}_{1}(\mathrm{kr}) \sin \theta \sin \psi-\mathrm{x}_{2}^{1}(0) \mathrm{J}_{2}(\mathrm{kr}) \sin 2 \theta \cos \psi\right\}
\end{aligned}
$$

Equations (15) to (17) give the solution to the elasticgravitational problem of a point nucleus of strike-slip in an elastic-gravitational layer over an elastic-gravitational half-space.

\section{Introduction of Viscoelasticity}

After the elastic Green's functions are computed, the correspondence principle of linear viscoelasticity is applied. This requires that the elastic quantities $\lambda$ and $\mu$ in each component of the elastic solution (each here represented by $u(t)$ ) be replaced by their Laplace-transformed quantities $s \bar{\lambda}(s)$ and $s \bar{\mu}(s)$ to obtain $\bar{u}(s)$, where the bar signifies the Laplace-transformed quantity and $s$ is the parameter conjugate to time. The $\bar{u}(s)$ is then inverted to give $u_{v}(t)$, the solution to the viscoelastic problem. The technique used to perform the inversion involves the Prony series, where the function $u_{v}(t)$ is approximated by a function $u_{v}{ }^{*}(t)$ comprised of a series of decaying exponential. Following Schapery [1961] and Cost [1964], we set

$$
u_{v}(t) \cong \sum_{i=1}^{N} A_{i} \tau_{i}\left(1-e^{-t / \tau_{i}}\right)=u_{v}^{*}(t)
$$

where $\cong$ means approximately equal to, in the least squares sense, $\left\{\tau_{i j}\right\}$ are a set of $N$ relaxation times, and the $A_{i}$ are a set of unknown constants that can be determined by a least squares method. The $\left\{\tau_{i j}\right\}$ was set equal to $\left\{0.5 \tau_{\mathrm{a}}, \tau_{\mathrm{a}}, 5 \tau_{\mathrm{a}}, 10 \tau_{\mathrm{a}}, 50 \tau_{\mathrm{a}}\right.$, and $\left.100 \tau_{\mathrm{a}}\right\}$ where $\tau_{\mathrm{a}}$, the characteristic relaxation time, is defined by $\tau_{a}=2 \eta / \mu$ and $\eta$ is the viscosity of the Maxwell fluid and $\mu$ is the elastic modulus. This approximation method has the advantage of smooth time domain results in the time interval required and involves as few function evaluations as possible. The error obtained using the numerical method is thus minimized. The $u_{v}{ }^{*}(t)$ can then be integrated over the source region to obtain the required solution.

\section{Results}

Postseismic viscoelastic deformation was calculated over timescales of 0 to $4 \tau_{\mathrm{a}}$. Effects due to the inclusion of gravity and from the variation of the fault parameters $\mu$ (Lame parameters of elastic layer and viscoelastic half-space), $D$ (depth of the fault), $W$ (width of the fault) and $\psi$ (dip angle) (Figure 1) are studied. Note 


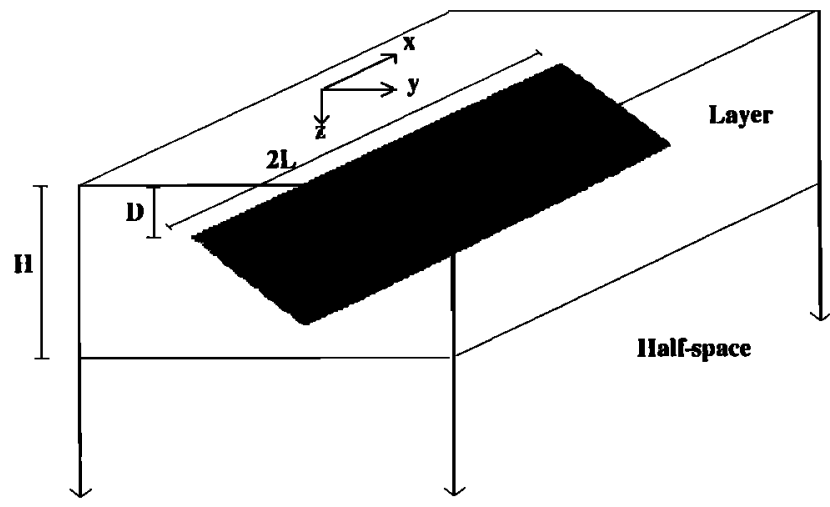

Figure 1. Geometry and coordinate system for a rectangular, dipping fault plane in an elastic-gravitational layer over a viscoelastic-gravitational half-space. $H$ is the thickness of the layer, $D$ is the depth of the fault, $2 L$ is the along strike length, $W$ is the downdip width, and $\psi$ is the dip. that Figures 2 and 3 illustrating postseismic displacement with and without gravitational effects for a vertical strike-slip fault have very similar patterns of displacement but are different in magnitude for the horizontal components in the far field, $X=200$ km, which are consistent with Rundle's [1981] results. Displacements in the non gravitational case have magnitude about one sixth the size of calculations with gravity. The amplitude of the postseismic deformation field changes somewhat as the magnitude of $\mu_{h}$ (Láme parameter of half-space) and $\mu_{l}$ (Láme parameter of elastic layer) is increased by a factor of 10 (Figure 4). The postseismic $U_{y}$ (displacement perpendicular to the strike of the fault) decreases in the vicinity of the fault, and the postseismic $U_{X}$ (displacement parallel to the strike of the fault) decreases in the amount of $20 \%$ for a vertical strike-slip fault profiled at far field, $X=200 \mathrm{~km}$.

The case of a vertical strike-slip fault that ruptures the entire elastic layer $(W / H=1)$ is shown in Figure 2. The predicted coseismic and postseismic deformation is the largest in the region
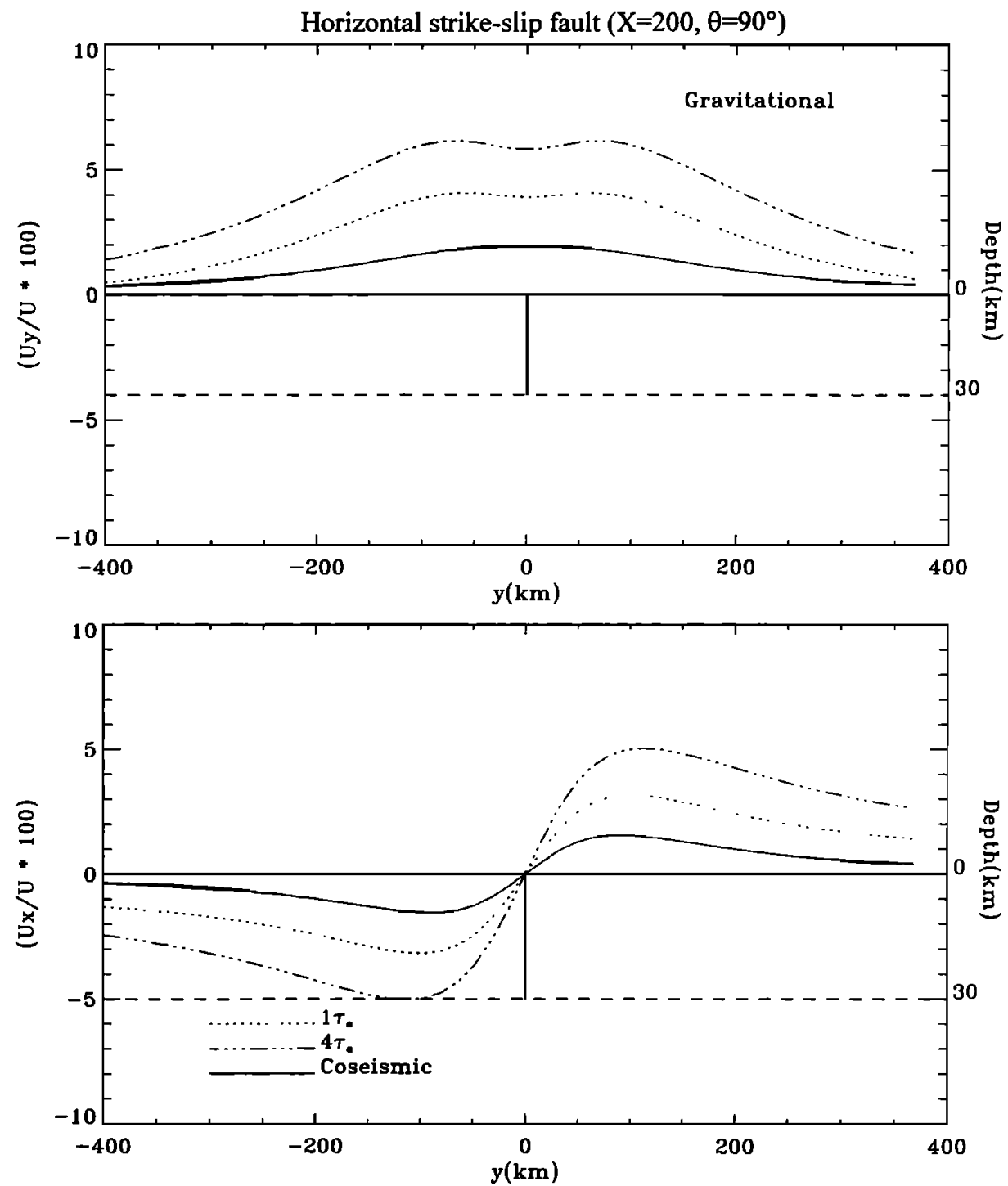

Figure 2. Surface horizontal deformation against distance normal to a strike-slip fault ruptures the entire elastic layer. Model parameters are $H=30 \mathrm{~km}, 2 L=200 \mathrm{~km}, \rho_{l}=\rho_{h}=3.0 \mathrm{~g} / \mathrm{cm}^{3}, \mu l=\mu_{h}=\lambda_{l}=\lambda_{h}=3 \times 10^{10} \mathrm{~Pa}$, (subscript $l$ denotes the elastic layer subscript $h$ denotes the viscoelastic half-space), $D / H=0, W / H=1, \psi=90^{\circ}$. The coseismic response is calculated using an elastic half-space where $\mu=\lambda=3 \times 10^{10} \mathrm{~Pa}$. The horizontal dashed line is the elastic layer half-space boundary, and the thick vertical line represents the fault plane geometry. The solid curve is the initial elastic response, and the dashed curves represent the deformation due to viscoelastic stress relaxation after $1 \tau_{\mathrm{a}}$ and $4 \tau_{\mathrm{a}}$. Each displacement profile has been evaluated at $100 \mathrm{~km}$ away from the end of the fault $(X=200 \mathrm{~km})$. 

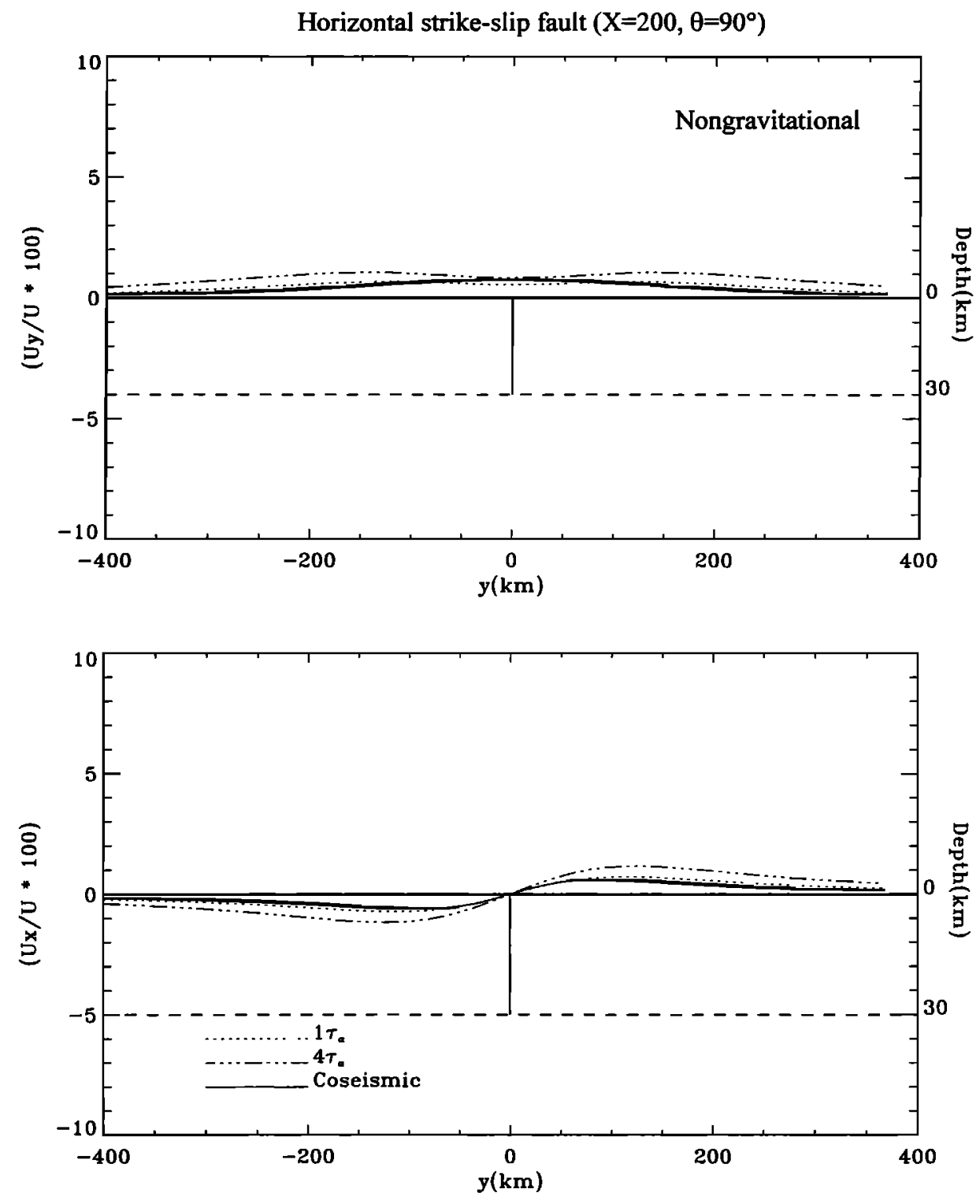

Figure 3. Surface horizontal deformations for vertical strike-slip fault without gravitational effect; the rest of the parameters are the same as Figure 2.

closest to the fault plane and decreases as the observation point moves away from the source. The maximum viscoelastic displacement $\left(U_{y}\right)$ occurs at a distance of twice the elastic layer thickness, in agreement with Cohen and Kramer [1984], and migrates outward with elapsed time. This phenomena reveal the important finding of Cohen and Kramer [1984, p.735] and Lehner and $L i$ [1982], "the surface deformation pattern is most sensitive to the rheology of the material that lies below the slip plane in a volume whose extent is a few times the fault depth". Displacements perpendicular to the fault $\left(U_{y}\right)$ are positive on both sides of the vertical strike-slip fault (Figure 2), but the parallel displacement $\left(U_{x}\right)$ is positive on one side, and negative on the other, in both the coseismic and postseismic intervals. The maximum viscoelastic displacement $\left(U_{x}\right)$ occurs at a distance about 3 times the thickness of the elastic layer and also migrates outward with time. Burying the strike-slip fault changes both the magnitudes of displacement, and the pattern. When the fault ruptures the bottom half of elastic layer (Figure 5), the maximum coseismic $U_{y}$ is located at about 3 times the thickness of the elastic layer away from center. The same width of fault ruptures the top half of the elastic layer (Figure 6) and produces the maximum elastic deformation at the center of fault, but the postseismic displacements have a longer wavelength. Response amplitude of a surface fault is about $20 \%$ larger than a buried fault at both directions. When the dip angle of the fault is other than vertical, both the coseismic and postseismic displacement patterns change (Figure 7). For a $30^{\circ}$ dipping strike-slip fault in the far field, $U_{y}$ has a maximum positive postseismic displacement in the region close to the fault and negative displacement on the upper block for distances greater than 6 times the thickness of elastic layer, similar to the coseismic $U_{y}$ in this region. Meanwhile, the coseismic $U_{y}$ remain positive on the lower block, and $U_{x}$ shows very little postseismic displacement in the region near the fault. At a distance roughly equal to the elastic layer, postseismic displacements have an opposing sign to the coseismic displacements on each side of the fault. Behavior of the displacement field is mainly controlled by the locations of the profile, within the fault plane or beyond the fault tips, and dipping angles. The displacement fields will migrate as time elapses, but they do keep a similar pattern at various intervals. Thickness of the elastic layer $(H)$, affects the 
Horizontal strike-slip fault $\left(X=200, \theta=90^{\circ}\right)$
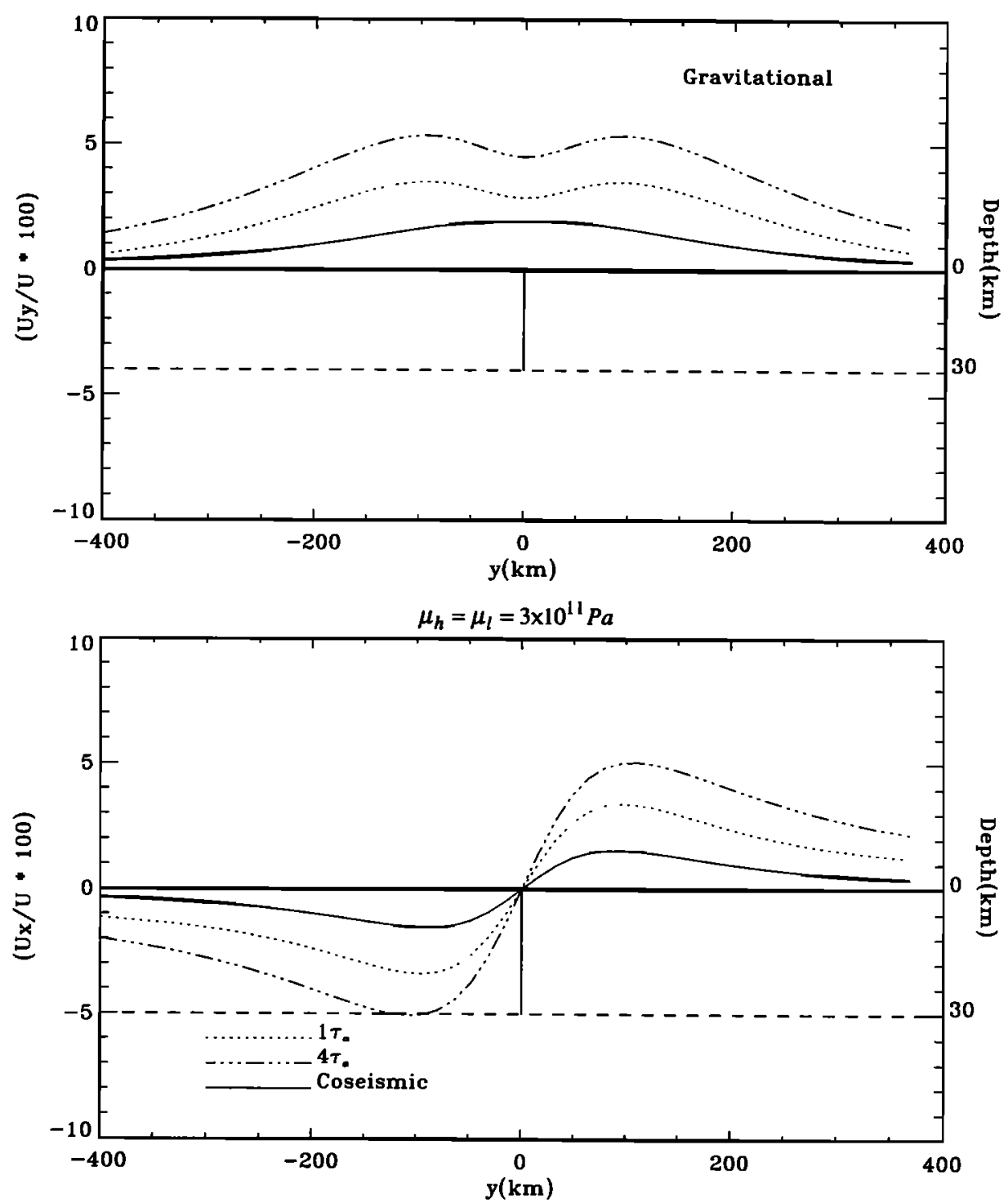

Figure 4. Surface horizontal deformations for larger Láme parameters at both elastic layer and viscoelastic halfspace, $\left(\mu_{l}=\mu_{h}=3 \times 10^{11} \mathrm{~Pa}\right)$; the rest of the parameters are the same as Figure 2 .

locations with extreme displacement at the surface. The inclusion of gravity and changing the shear modulus will affect the magnitude only, not the displacement pattern.

Figure 8 shows the spatial patterns of displacement in map view. The maximum viscoelastic displacement after $4 \tau_{a}$ is about one fifth the size of the maximum coseismic displacement, and the location of maximum displacement clearly migrates away from the fault as time elapses. A clockwise pattern of motion is found at the fault tips in postseismic displacement fields.

For a vertical strike-slip fault, the magnitude of the vertical postseismic displacement field is negligible fraction of the coseismic displacement, and the pattern of vertical displacement is very similar to the parallel displacement $U_{x}$ (Figure 9) for a profile across the edge of the fault $(X=100 \mathrm{~km})$. Magnitudes of the coseismic vertical displacement at the center of the fault increased by 7 times when the dip angle changed from vertical to $30^{\circ}$, and the viscoelastic displacement becomes $200 \%$ in magnitude of coseismic displacement. The inclusion of gravity changes the vertical postseismic displacement of the dipping strike-slip fault, although the absolute values are still negligible compared to the horizontal displacement.

\section{Test Case: Landers Earthquake}

As an example application, we fit a sample of the postseismic displacements for the Landers earthquake. While the usual method is to model their displacements by postseismic slip, it is instructive to try explaining them via viscoelastic relaxation.

We use baselines from station 7000 to 7001 and DS10 to WIDE from the Landers earthquake network (Figure 10). The reason for choosing these baselines is that 7000-7001 crosses the surface rupture of the main shock, and baseline DS10-WIDE covers most of the surveyed region. Shen et al. [1994] used the velocity model of southern California to construct "the prior correction" to remove the displacements due to tectonic processes. In their model, the prior correction for the baseline 7000-7001 is 0 for the east component, and $0.4 \mathrm{~mm} / \mathrm{yr}$ for the north. The 

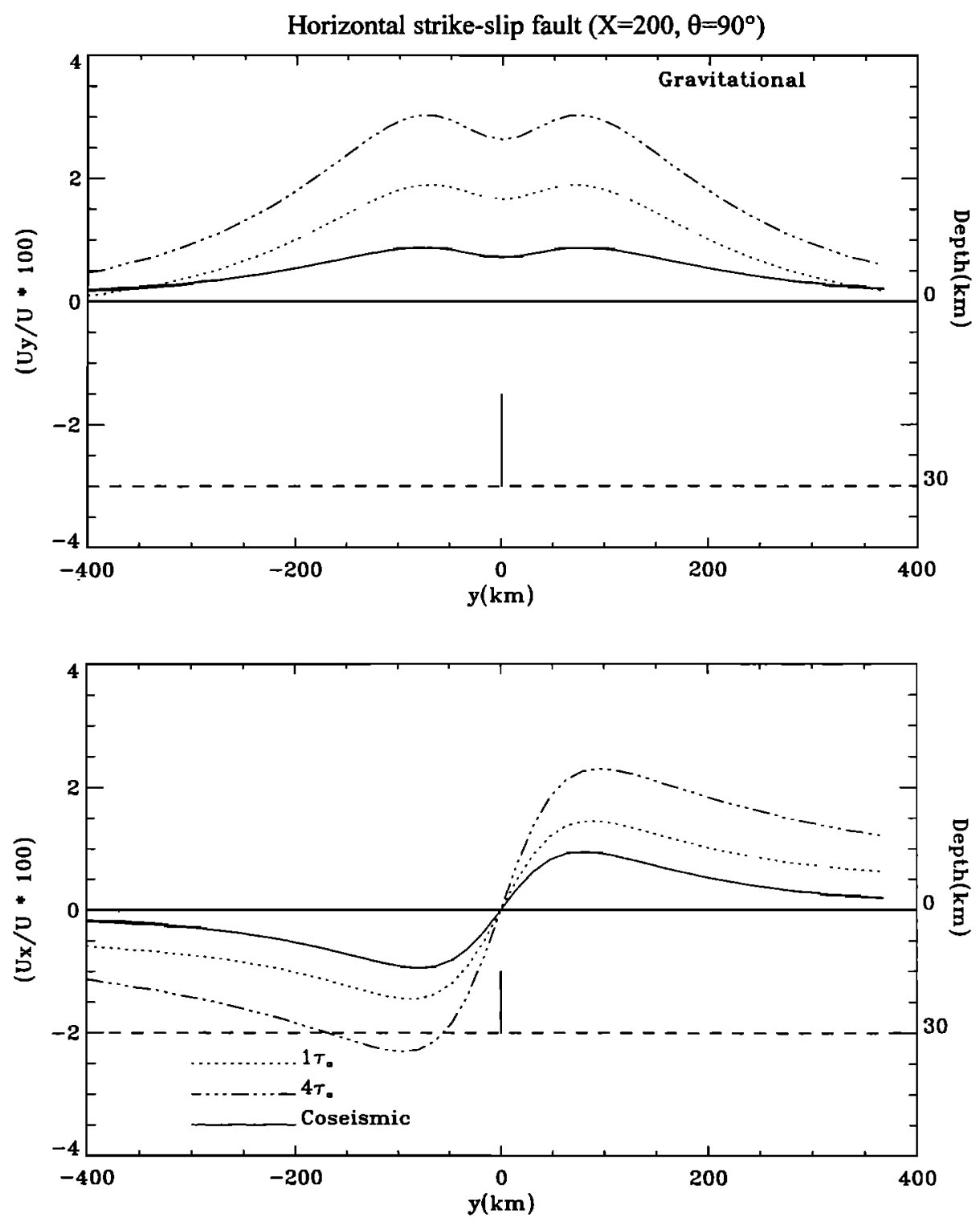

Figure 5. Surface horizontal deformations for a buried vertical strike-slip fault, $D / H=0.5$, and $W / H=0.5$. ( $D$ is the depth of fault, $H$ is the thickness of elastic layer and, $W$ is the width of the fault.)

correction for baseline DS10-WIDE is $6.9 \mathrm{~mm} / \mathrm{yr}$ for east and $\mathbf{- 3 . 8}$ $\mathrm{mm} / \mathrm{yr}$ for north component. We test the hypothesis that during the measuring period, 200 days after the main shock, viscoelastic displacement caused by the main shock could be the primary agent for the changes of baselines. The GPS data were fit and shown in Figures $10 \mathrm{a}$ and $10 \mathrm{~b}$. The parameters used in this computation are derived from Shen et al. [1994]: $10 \mathrm{~km}$ for the elastic layer thickness, $42 \mathrm{~km}$ for the length of the fault, a dip angle of $90^{\circ}$, and an average dislocation of $1 \mathrm{~m}$ over the entire ruptured fault zone. The relaxation time is $\mathbf{3 4}$ days, which is considerably shorter than the years-to-decades normally found for postseismic relaxation [e.g., Thatcher and Rundle, 1984]. We found a reasonable agreement between model and data. We also note that our results are not unexpected, as postseismic slip and viscoelastic relaxation are well known to give similar spatial pattern [e.g., Savage, 1983]. However the 34 days relaxation time $\left(\eta=6 \times 10^{17} \mathrm{P}\right)$ is very short compared to times found in previous works, 2.5 to 20 years [e.g. Nur and Mavko, 1974; Spence and Turcotte, 1979]. This could be due to transient effects after the main shock or to the existence of a weak "intra-crustal layer" as proposed by Turcotte et al. [1984]. They proposed a depth for this layer of 10-12 km in southern California, which matches well with our model. In the Turcotte et al., [1984] model, the stresses can relax in this layer due to the presence of quartz or mobile pore fluids. More evidence is needed to distinguish the relaxation mechanism from these two possible sources in this case.

\section{Simulating the Earthquake Cycle}

We have constructed a model for the earthquake cycle using the model described by Savage and Prescott [1978] to calculate the components of deformation $\left(U_{x}, U_{y}\right.$, or $\left.U_{z}\right)$ measured at time $t$ after the most recent earthquake:

$$
\begin{aligned}
w(\underline{x}, t)=-w_{1}(\underline{x}, \infty) t / T+w_{1}(\underline{x}, t)+\sum_{n=l}^{N}\left\{w_{1}(\underline{x}, t+n T)-\left[w_{1}(\underline{x}, n T)\right]\right\}, \\
0<\mathrm{t}<\mathrm{T}
\end{aligned}
$$



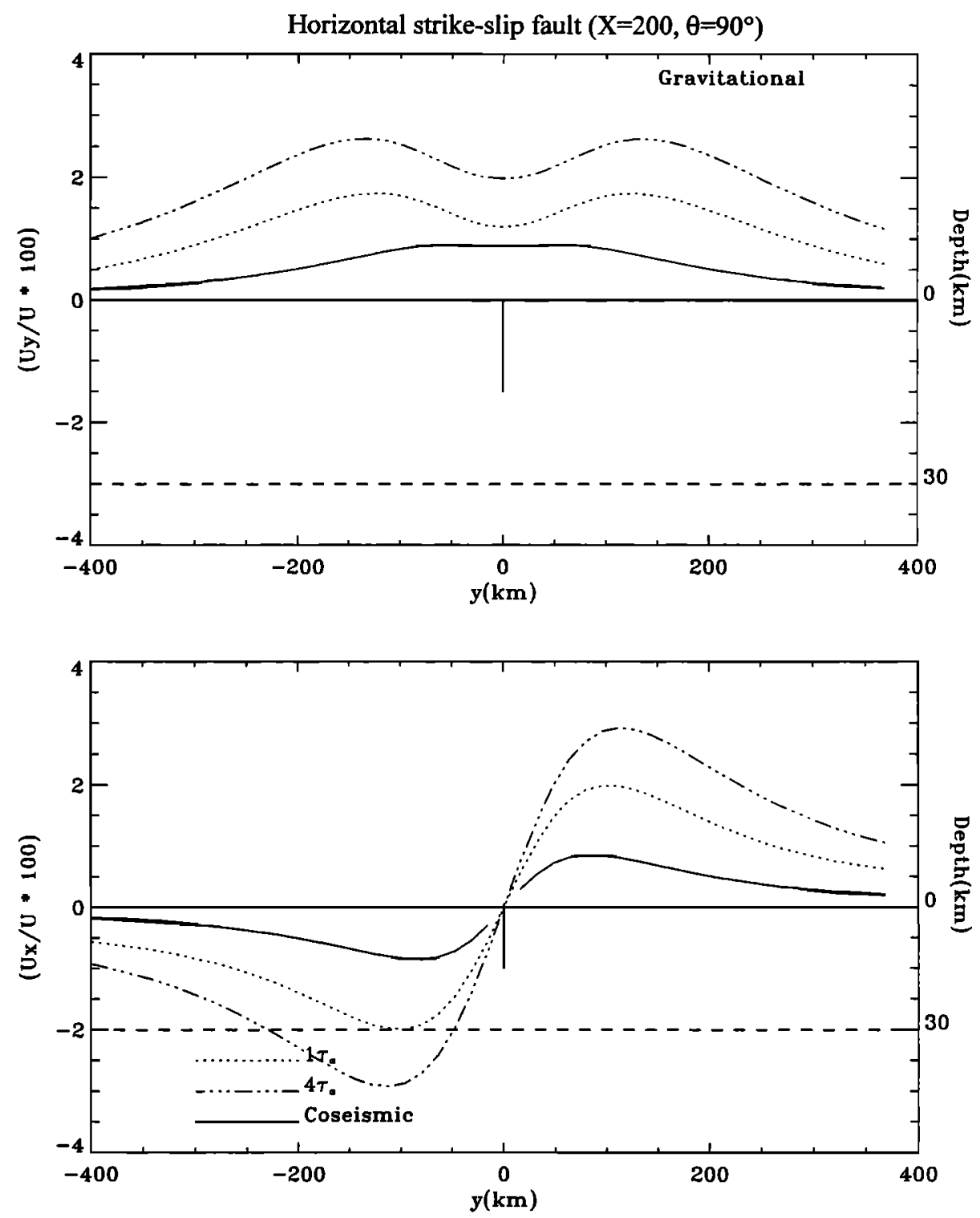

Figure 6. Surface horizontal deformations for a surface vertical strike-slip fault ruptures the top half of the elastic layer, $D / H=0$, and $W / H=0.5$.

where $w(x, t)$ represent a component of the deformation field, $w_{l}(x, \infty) / T$ is the response to a steady motion of long duration, $w_{l}(\underline{x}, t)$ is the postseismic deformation due to the most recent event, and the last term is the viscoelastic contribution from previous events. This model represents elastic plates driven with constant relative velocity $V$ locked to a depth $D$ between earthquakes, having $N$ prior events reoccurring at uniform interval $T$.

Most of the attempts to model the time-dependent tectonic phenomena after earthquakes used two-dimensional models [e.g. Nur and Mavko, 1974; Savage and Prescott, 1978; Thatcher and Rundle, 1984] or simple layer and half-space solutions [e.g. Rundle and Jackson, 1977; Cohen, 1980a, b]. Two-dimensional models assume an infinite long fault, neither the effects in the region beyond the fault tip nor the inclusion of gravity cannot be described. However, in this paper we show that there are significant effect in the region beyond the fault tip, and inclusion of gravity also affects the surface displacement field for strike-slip events. For comparing our model to the 2D simplified model, the same parameter settings was considered to generate a single earthquake cycle with duration $\tau_{0}=1, D / H=0.5$ [e.g. Savage and Prescott, 1978, Figure 4]. The results of our model are shown in Figure 11a, the results of the 2D model are shown in Figure 11b, and time-dependent displacements obtained by finite element are shown in Figure 11c [e.g. Cohen, 1982, Figure 2] for comparison. The major difference between our 3D and 2D model is the decay of displacement as it moves away from fault. In the $2 \mathrm{D}$ model, the fault paralleling displacement $\left(U_{x}\right)$ is zero in infinite distance away from fault but shows almost constant in the region closer than 5 times thickness of the elastic layer. On the other hand, the analytic (Figure 11a) or finite element solution (Figure 11 c) shows a dramatic decay in both the coseismic and postseismic intervals. Besides the difference in decay pattern, the 2D model did not consider the gravity, finite fault length, various dip angles, and more realistic rupture plane. The rupture source used in the 2D model either is skew or edge dislocation, which caused the 

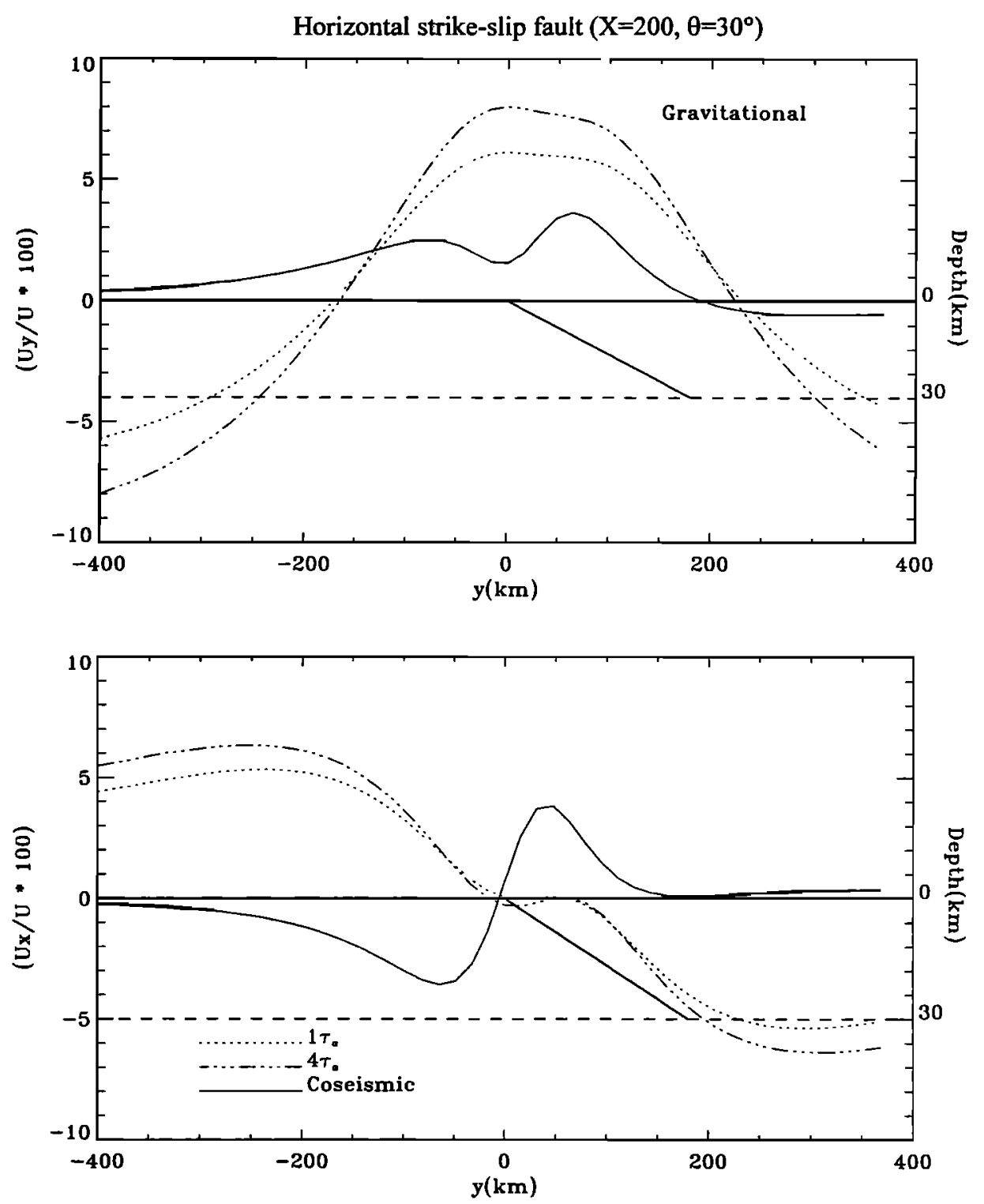

Figure 7 Surface horizontal deformations for dipping strike-slip fault, $\psi=30^{\circ}, D / H=0$, and $W / H=1$.

discontinuity in slip at depth $D$. Therefore our detailed, threedimensional time-dependent model is necessary for the interpretation of high accuracy geodetic measurements.

To sketch the viscoelastic displacement caused by the cyclic earthquakes during various time intervals, we set the recurrence times equal to $1 \tau_{\mathrm{a}}$ and $100 \tau_{\mathrm{a}}$ on Figures 12 and 13 , respectively. The relative plate velocity $V=U / T$, where $U$ is the dislocation on the fault for each earthquake. As we expect, the plate motion dominates the accumulated viscoelastic displacements for all events at short recurrence time intervals (Figure 12). When $T$ becomes 100 times the relaxation time (Figure 13), a "looping" pattern of displacement is found near the fault, caused by the change of accumulated viscoelastic displacements in direction $U_{y}$. For the long recurrence time intervals obtained by setting $T=100 \tau_{\mathrm{a}}$, the "looping" pattern migrates out from the fault as time elapses (Figure 13). This pattern thus serves as a time index for the various stages of a long recurrence interval of cyclic strike-slip earthquake.

\section{Summary and Discussion}

A previous method is extended to calculate the postseismic surface displacements resulting from slip on a strike-slip fault in an elastic layer overlying a viscoelastic half-space. The effects of gravity are found to produce minimal differences in the displacement fields near the fault. At larger distances away from fault, the presence of gravity significantly changes the horizontal displacement due to a vertical strike-slip fault. For vertical displacement due to a dipping strike-slip fault, gravity influenced the magnitude as much as $\mathbf{4 0} \%$. In addition, by inverting the geodetic measurements acquired after major earthquakes, we can find better constrains for the viscoelastic properties of asthenosphere with this detailed 3D model. We also found that burying the strike-slip fault changes both the magnitude and pattern of displacement field in our model. It suggests that it is possible to determine whether a fault extends completely or partially through the elastic layer by an inspection of the pattern of 

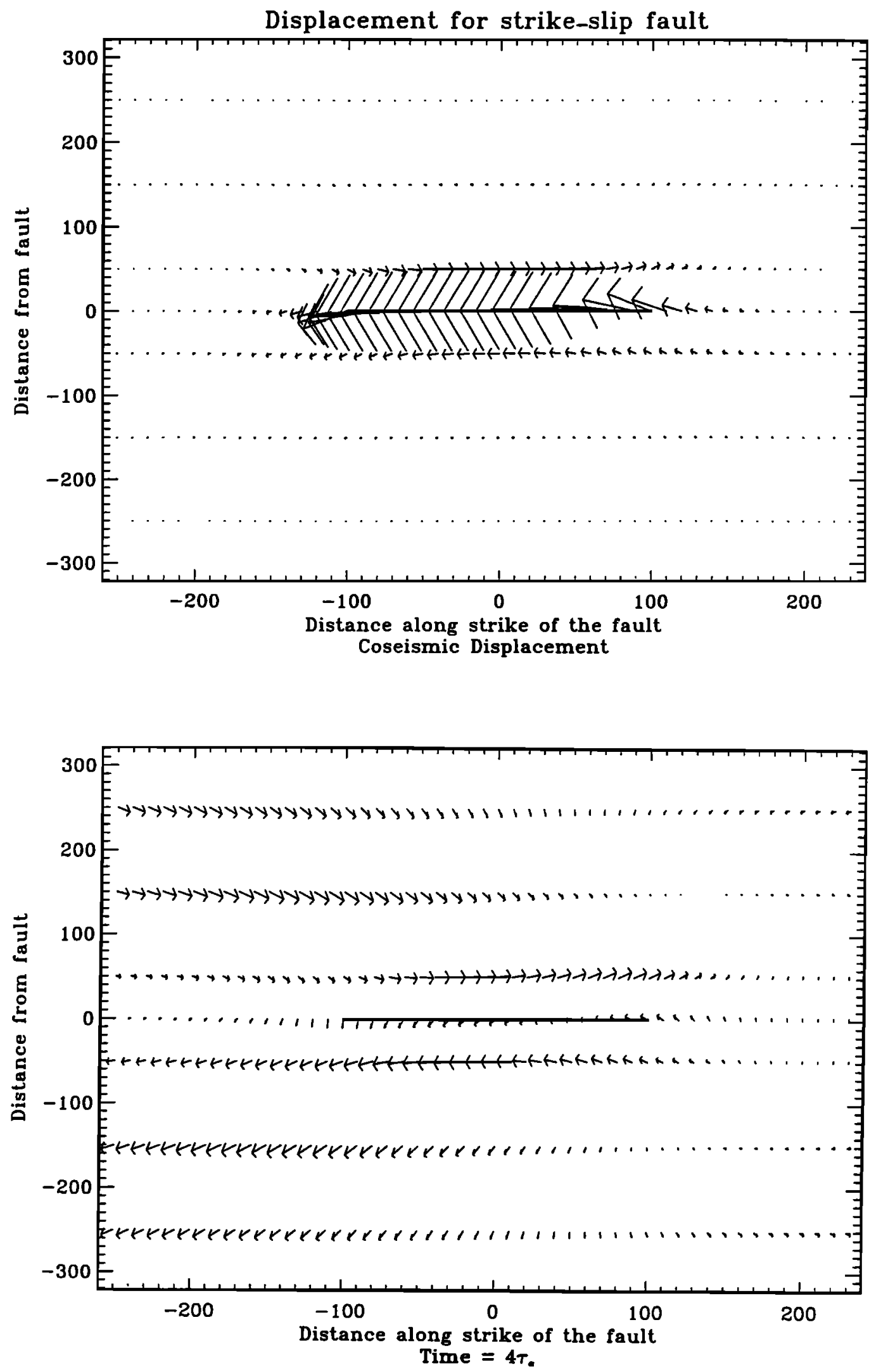

Figure 8. Map view of (top) coseismic and (bottom) postseismic displacement with the same parameters as Figure 2, thick line at center of the map represents the fault. The maximum displacement near the fault is $4.86 \mathrm{~cm}$ in the top panel. The postseismic displacement at time equal to $4 \tau_{\mathrm{a}}$ is shown, and the maximum displacement at far field is 0.97 $\mathrm{cm}$ in the bottom panel. 


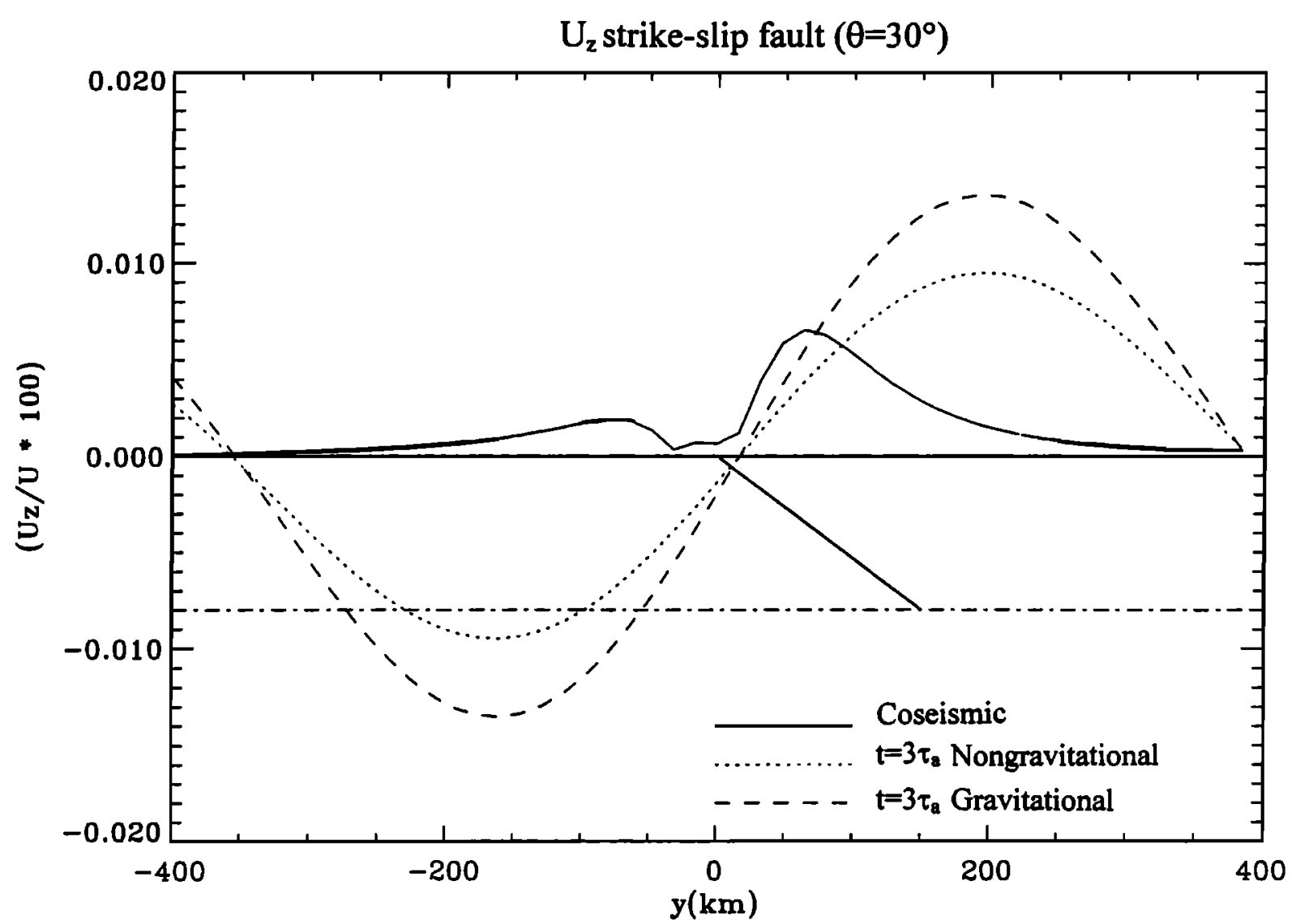

Figure 9. The vertical displacement due to a $30^{\circ}$ dipping strike-slip fault, both the postseismic displacements with and without gravity are shown.

coseismic and postseismic deformation fields. However, to serve such a purpose, a highly accurate geodetic observation and detailed tectonic structure model for the target region is required.

The boundary conditions contained in the present version of the model, however, do not account for data that are affected by repeated events. The method appropriate to these circumstances is outlined by Savage and Prescott [1978], and the application of this will form a particularly valuable tool for interpreting observed geodetic surface deformation in areas of active strike-slip faulting and for forward modeling at transform faults. The 2D model by Savage and Prescott [1978] is constructed with an infinite long vertical strike-slip fault, and the time and dip angle dependent postseismic $U_{x}$ and $U_{y}$ found in this study cannot be modeled with the simplified 2D model. However, the model we have constructed has no such limitation: the influence of fault parameters, time constraint, and numbers of the previous event can be modeled.

As with all layered viscoelastic calculations, our model predicts the presence of a long wavelength component in the postseismic deformation field following a single event that migrates with time. This result is also seen in models with continued slip at depth in an elastic half-space [Savage, 1983], however, in those cases, the after-slip time function must be assumed. One possible distinction between these two models lies in the analysis of the distribution of observed deformation with time. Here we demonstrate a nonlinear spatial variation of displacement with time. For a similar distribution of displacements to occur using the continued slip at depth hypothesis, a fault continually evolving in depth (to fit the magnitude), downdip width, and angle (to fit the pattern) would have to be incorporated into the model. Data sets of sufficiently high quality are now becoming available, presenting the possibility of discriminating between these two ideas. If a difference can be detected, this will lead to a better understanding of the physical processes responsible for strike-slip faulting. The good fit between calculated results and GPS measurements of the Landers earthquake suggest that viscoelasticity may be an important factor for strike-slip events, just as it as for dip-slip events.

Vertical viscoelastic displacements are insignificant compared to coseismic displacements, but the horizontal coseismic and postseismic displacements have roughly the same magnitude. Finally, earthquake cycle models can be constructed such that, in certain circumstances (i.e., $T \gg \tau_{\mathrm{a}}$ ), they provide a means of identifying in what stage of the earthquake cycle a given fault system occurs. 
(a)
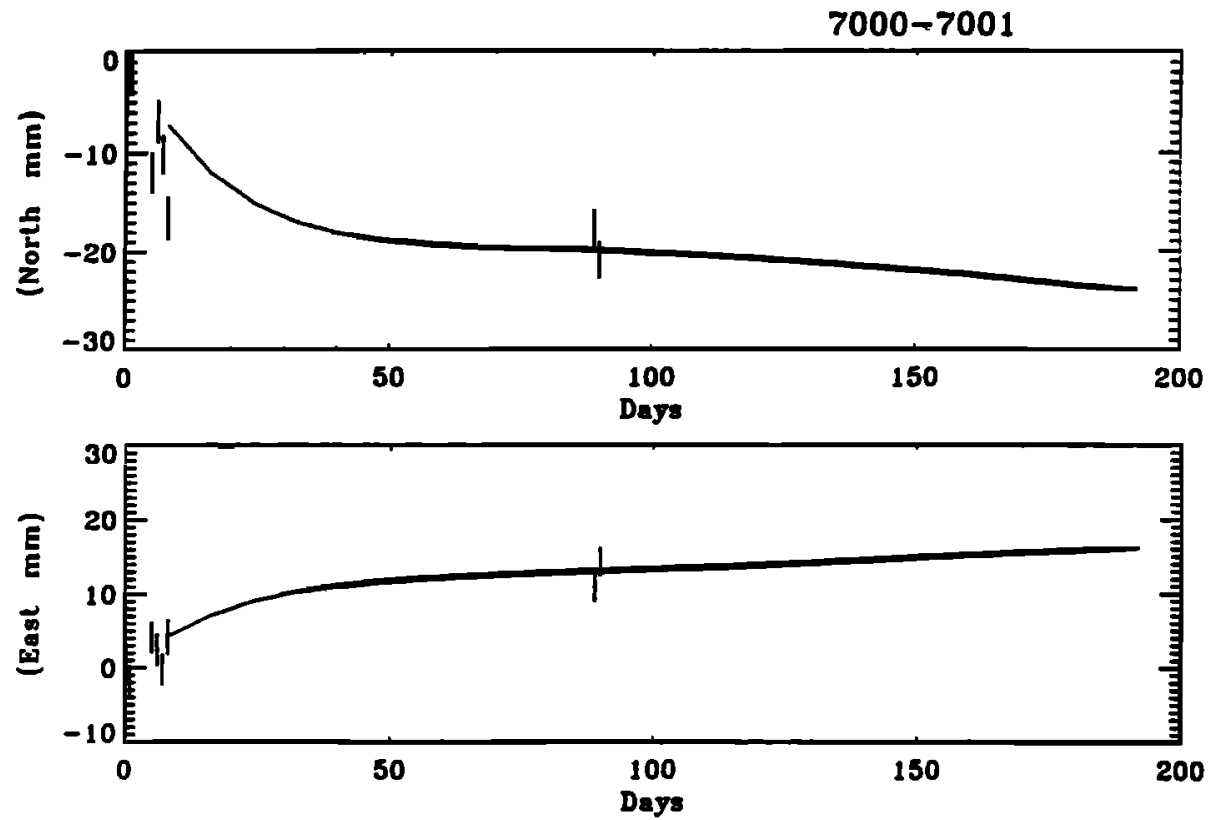

(b)
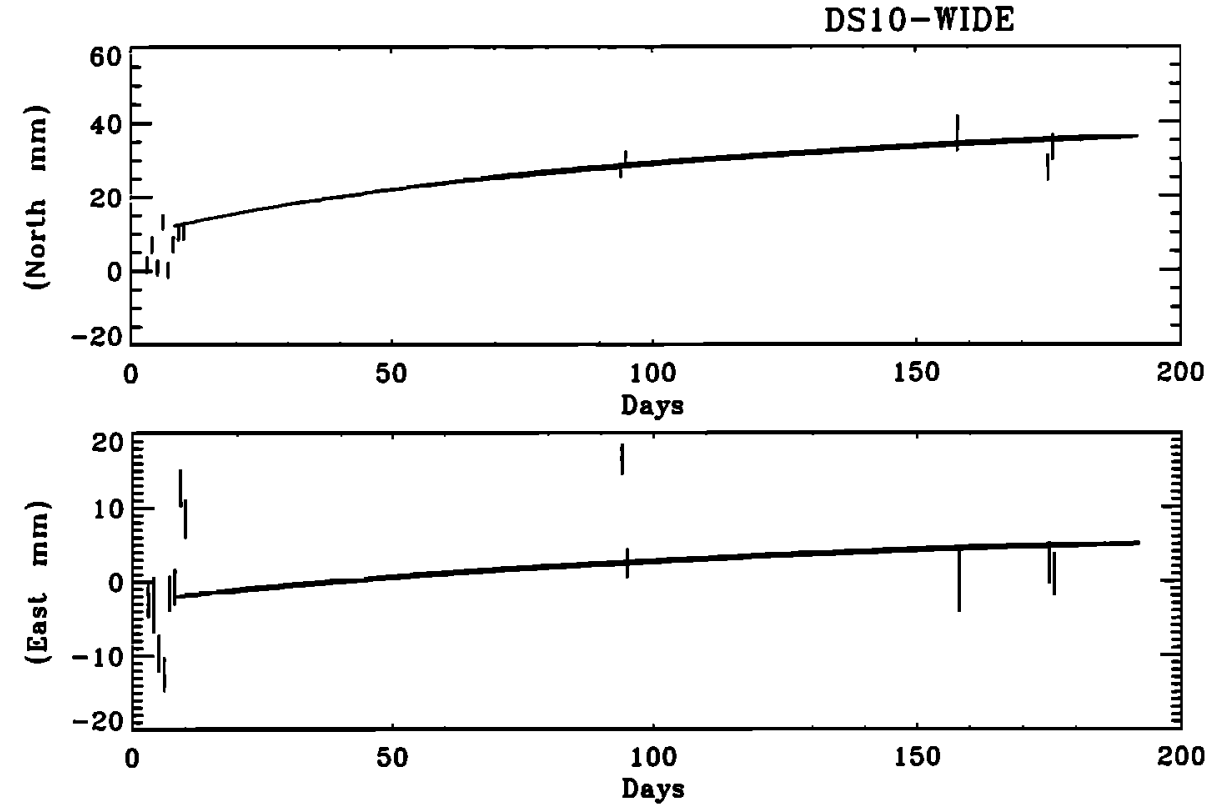

(c)

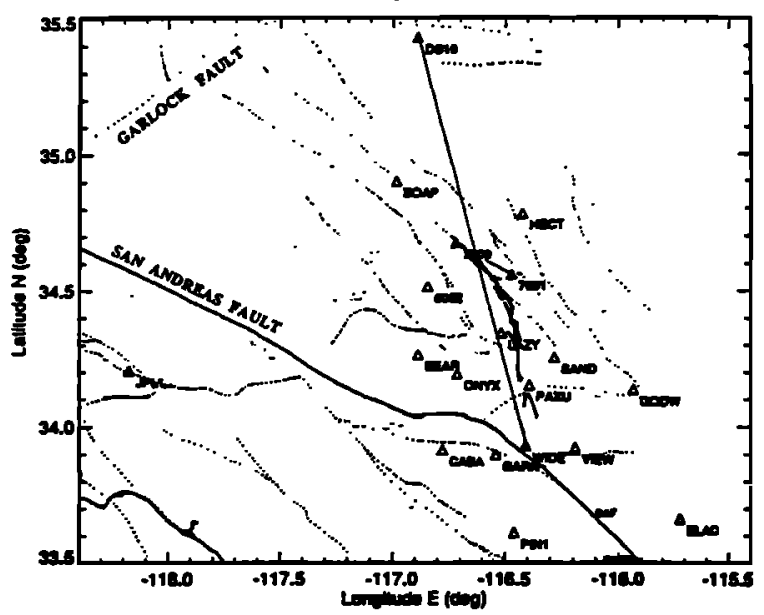

Figure 10. (c) The location map of Global Positioning System (GPS) stations at the Landers earthquake network, the thick curve between station 7000 and 7001 is the surface rupture zone of the 1992 Landers earthquake. The dark triangle is the stations used in this study, open triangle is the other GPS stations at the network, modified after Shen et al., [1994]. (a) The comparison between GPS data (vertical lines) and the computed results (solid curve) for baseline 7000-7001, and (b) for baseline DS10-WIDE at the period of 200 days after main shock of the Landers earthquake in 1992 are shown. 
(a)

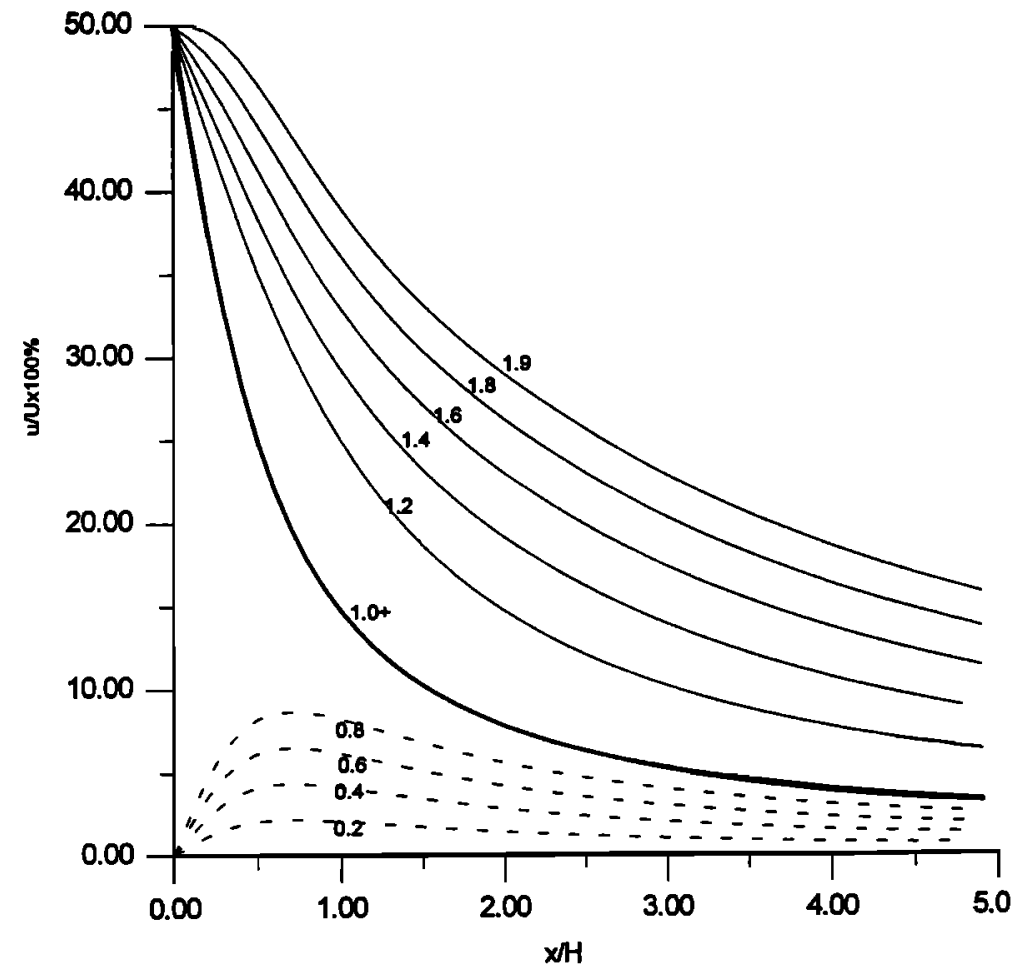

(b)

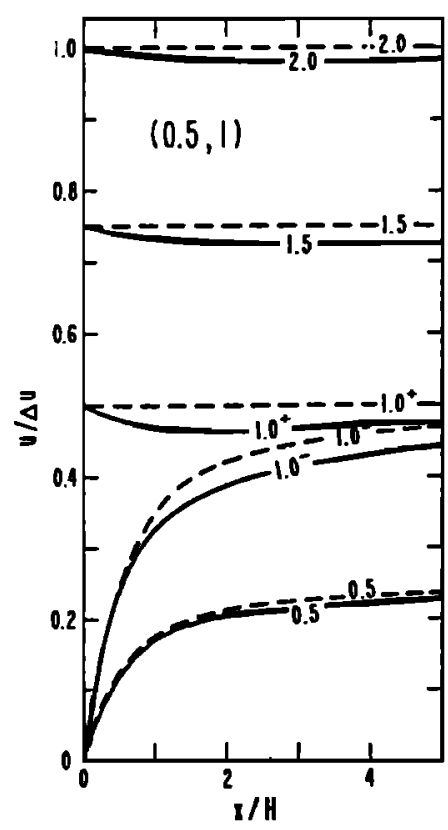

(c)

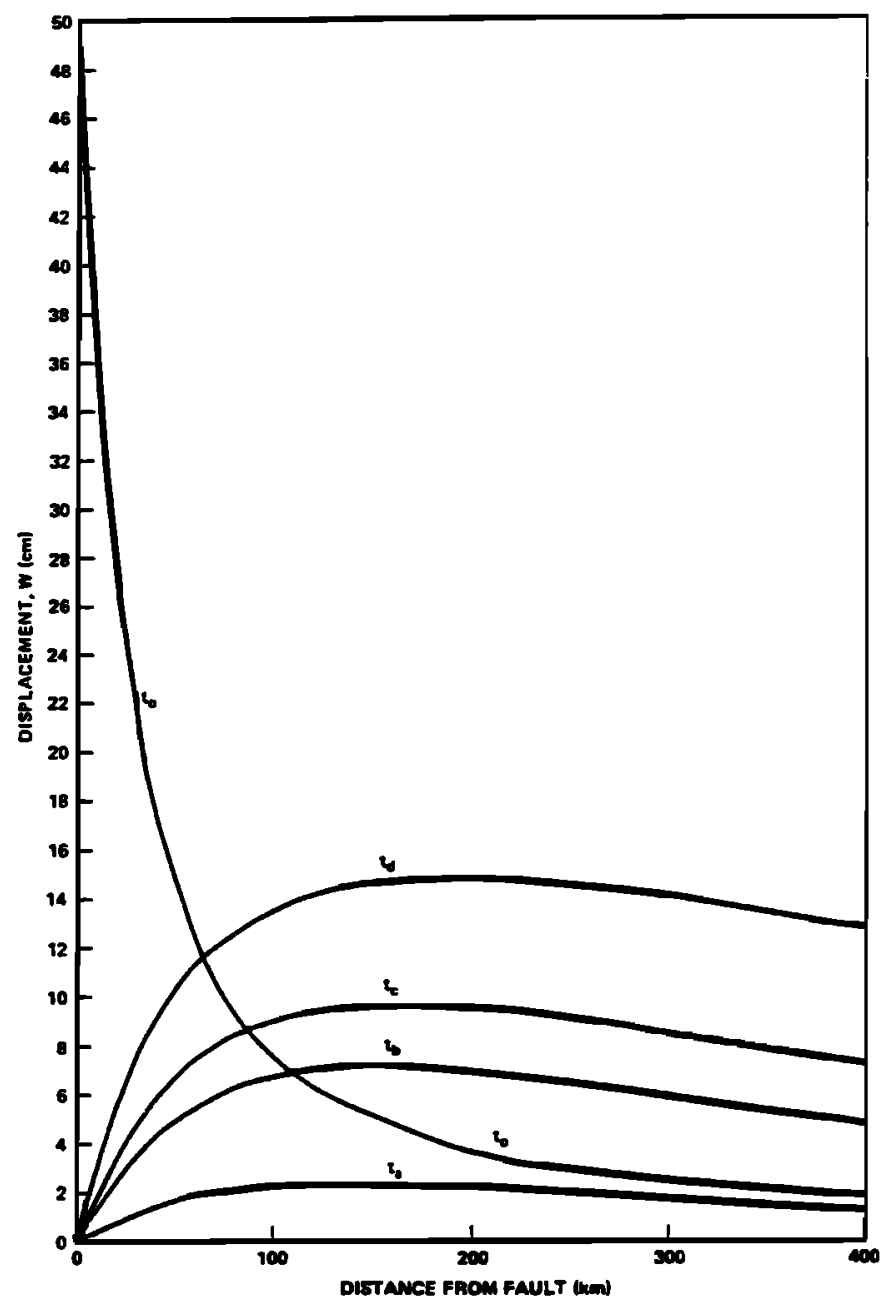

Figure 11. Ratio of the surface displacement $u$ to coseismic slip $U$ as a function of distance from the fault at various times $\tau$ for a single earthquake cycle of duration $\tau_{0}=1$ in (top) the 3D gravitational model and (bottom left) the Nur-Mavko Earth model [after Savage and Prescott, 1978] with $D / H=0.5$. $H$ is the thickness of the elastic layer. The notation in each line shows the ratio of $t / T$, where $T$ is the recurrence time. (bottom right) Displacement versus distance obtained by 3D finite element model is shown; coseismic displacement at time $t_{0}$ is shown; and postseismic displacements $\left(\Delta W=W(t)-W\left(t_{0}\right)\right.$ at various times [after Cohen, 1982] are shown. 

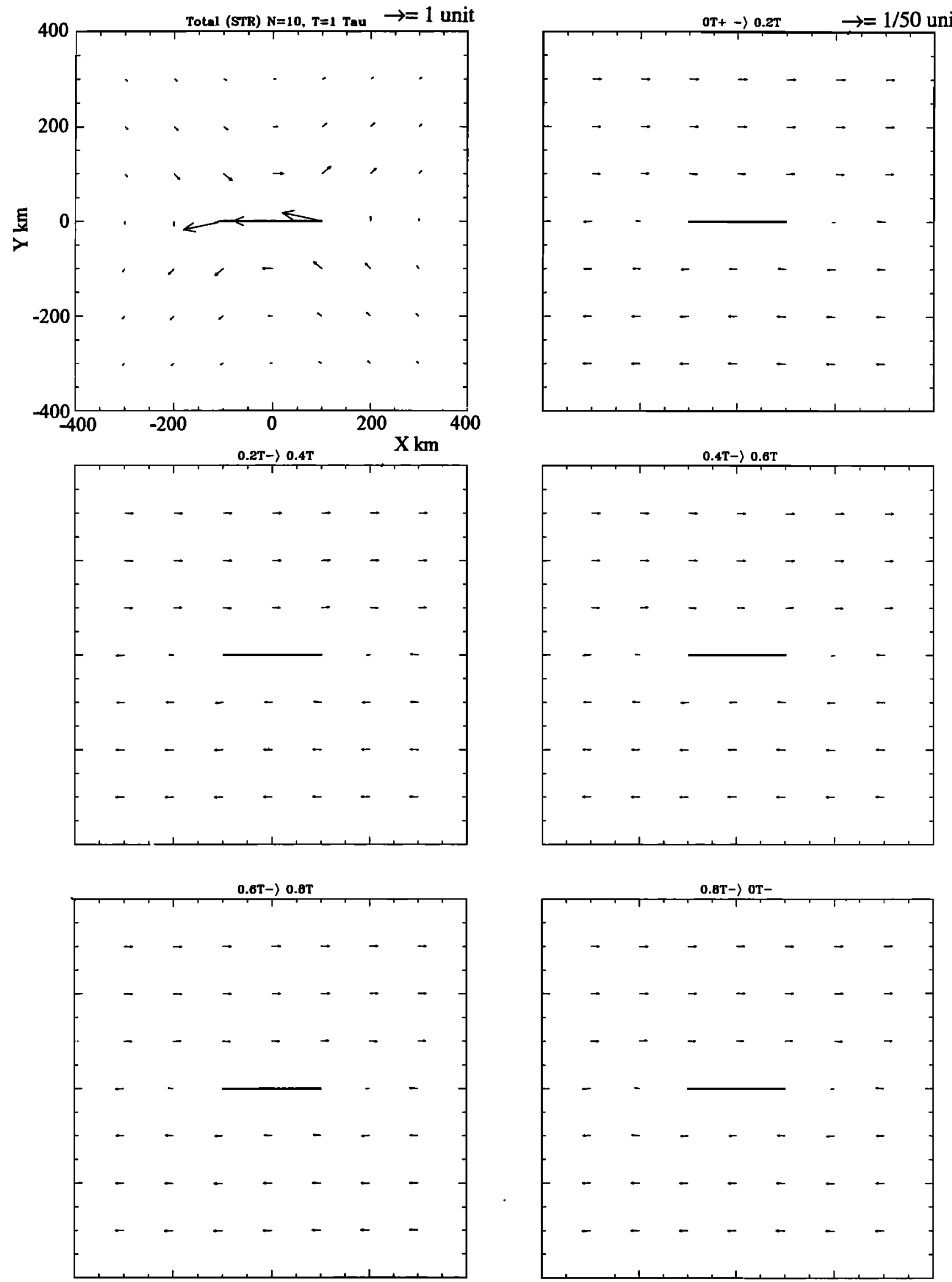

Figure 12. The accumulated displacement field due to 10 earthquakes prior to the event and with the recurrence time equal to 1 relaxation time. The thick line at center of the plot represents the reputed fault plane (upper left). The scale of the velocity field (size of arrows) other than the coseismic plots is $1 / 50$ of the coseismic one. 

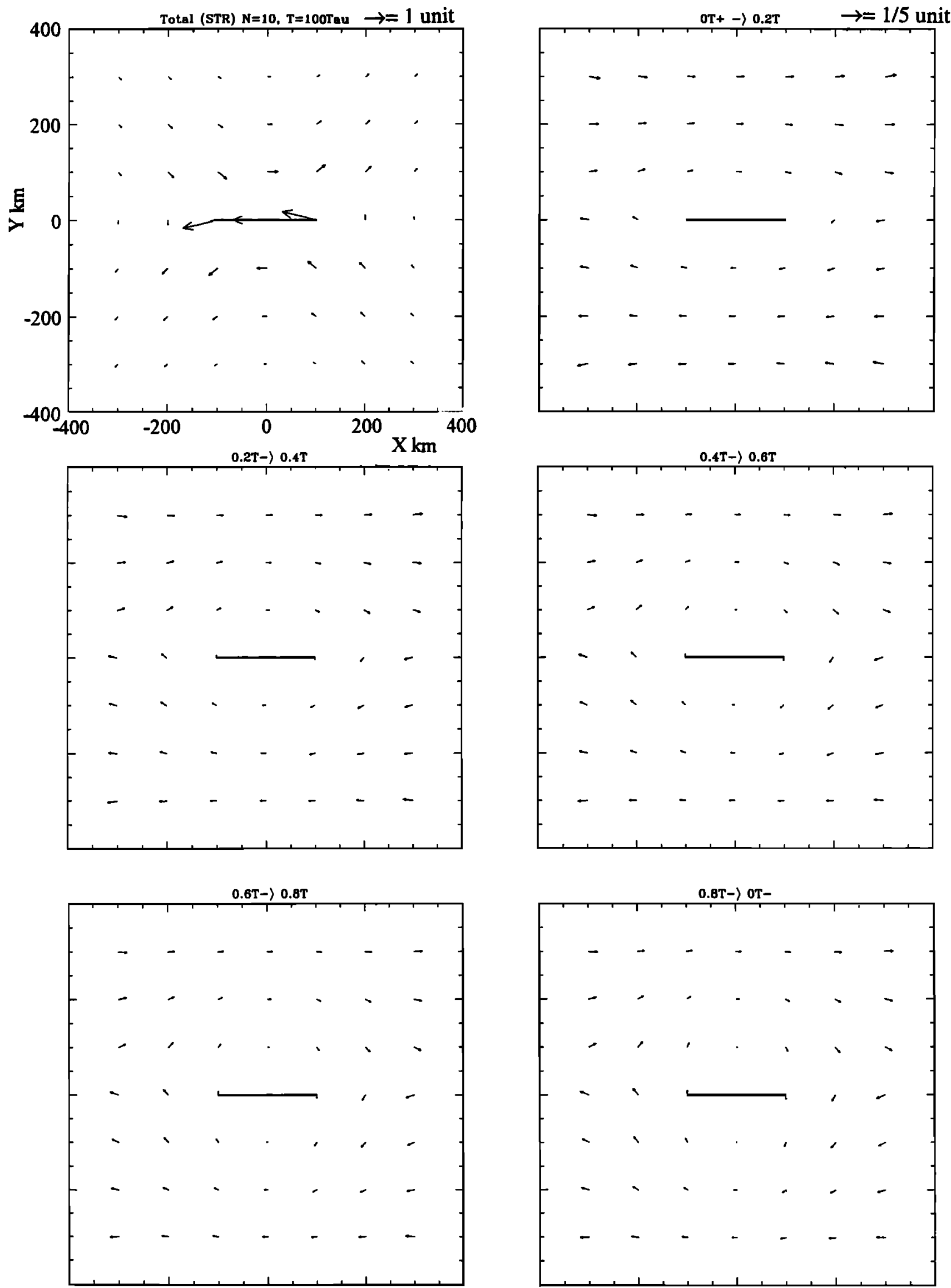

Figure 13. The same as Figure 12 except that $T=100$ is the relaxation time. Note the scale for non-coseismic plots is 10 times larger than Figure 12 (upper left). The scale of the velocity field ( size of arrows) other than the coseismic plots is $1 / 5$ of the coseismic one. 
Acknowledgments. The research of John B. Rundle and Ting-To Yu has been supported by NASA grant NAG5-2353, and the research of J. Fernández was supported with funds from project EVSV-CT92-0173 of the European Union in the frame of the Environment Program and by the Consejeria de Educacion y Cultura of the Comunidad de Madrid, which provided funds for his stay at CIRES, University of Colorado at Boulder. We thank Steven $C$. Cohen and Wayne Thatcher for reviewing the manuscript and giving us valuable suggestions and comments to improve the manuscript. We thank Michael Kozuch for reading the manuscript and D. D. Jackson for providing us with the Landers GPS data set.

\section{References}

Ben-Menahem, A., and S. J. Singh, Multipolar elastic fields in a layered half-space, Bull. Seismol. Soc. Am., 58, 1519-1572, 1968.

Chinnery, M. A., Deformation of the ground around surface faults, Bull. Seismol. Soc. Am., 51, 355-372, 1961.

Cohen, S. C., Postseismic viscoelastic surface deformation and stress, 1 , Theoretical considerations, displacements, and strain calculations, $J$. Geophys. Res., 85, 3131-3150, 1980a.

Cohen, S. C., Postseismic viscoelastic surface deformation and Stress, 2 , Stress theory and computation: Dependence of displacement, strain and stress on fault parameters, J. Geophys. Res., 85, 3151-3158, $1980 \mathrm{~b}$.

Cohen, S. C., A multilayer model of time dependent deformation following an earthquake on a strike-slip Fault, J. Geophys. Res., 87, 5409-5421, 1982.

Cohen, S. C., and M. J. Kramer, Crustal deformation, the earthquake cycle, and models of viscoelastic flow in the asthenosphere, Geophys. J. R. Astron. Soc., 78, 735-750, 1984.

Cost, T. L., Approximate Laplace transform inversions in viscoelastic stress analysis, ALAA J., 2 2157-2166, 1964.

Fitch, T. J., and C. H. Scholz, Mechanism of underthrusting in southeast Japan: A model of convergent plate interactions, J. Geophys. Res., 76, 7260-7279, 1971.

Hofton, M. A., J. B. Rundle, and G. R. Foulger, Horizontal surface deformation due to dike emplacement in an elastic-gravitational layer overlying a viscoelastic-gravitational half-space, J. Geophys. Res., 100, 6329-6338, 1995

Jovannovich, D. B., M. I. Husseini, and M. A. Chinnery, Elastic dislocations in a layered half-space, I, Basic theory and numerical methods, Geophys. J. R. Astron. Soc., 39, 205-217, 1974.

Lehner, F. K., and V. C. Li, Large-scale characteristics of plate boundary deformations related to the post-seismic readjustment of a thin asthenosphere, Geophys. J. R. Astron. Soc., 71, 775-792, 1982.

Li, V. C., and J. R. Rice, Crustal deformation in great California earthquake cycles, J. Geophys. Res., 92, 11,533-11,551, 1987.

Love, A. E. H., Some Problems of Geodynamics, Cambridge Univ. Press, New York, 1911.

Ma, X. Q., and N. J. Kusznir, 3-D subsurface displacement and strain fields for faults and fault arrays in a layered elastic half-space, Geophys. J. Int., III, 542-558, 1992.

Ma, X. Q., and N. J. Kusznir, Modeling of near-field subsurface displacements for generalized faults and fault arrays, J. Struct Geol, 15, (12), 1471-1484, 1993.
Ma, X. Q., and N. J. Kusznir, Effects of rigidity layering, gravity and stress relaxation on 3-D subsurface fault displacement fields, Geophys. J. Int., 118, 201-220, 1994.

Matsu'ura, M., and T. Tanimoto, Quasi-static deformations due to an inclined, rectangular fault in a viscoelastic half-space, $J$. Phys. Earth, $28,103-118,1980$.

Nur, A., and G. Mavko, Postseismic viscoelastic rebound, Science, 183, 204-206, 1974.

Pollitz, F., Postseismic relaxation theory on the spherical Earth, Bull. Seismol. Soc. Am., 82, 422-453, 1992.

Rundle, J. B., Viscoelastic crustal deformation by finite, quasi-static sources, J. Geophys. Res., 83, 5937-5945, 1978.

Rundle, J. B., Static elastic-gravitational deformation of a layered halfspace by point couple sources, J. Geophys. Res., 85, 5354-5363, 1980.

Rundle, J. B., Vertical displacements from a rectangular fault in layered elastic-gravitational media, J. Phys. Earth, 29, 173-186, 1981.

Rundle, J. B., and D. D. Jackson, A three dimensional viscoelastic mode of a strike-slip fault, Geophys. J. R. Astron. Soc., 49, 575-591, 1977.

Savage, J. C., A dislocation model of strain accumulation and release at subduction zone, J. Geophys. Res., 88, 4984-4996, 1983.

Savage, J. C., and W. H. Prescott, Asthenosphere readjustment and the earthquake cycle, J. Geophys. Res., 83, 3369-3376, 1978.

Schapery, R. A., Approximate methods of transform inversion for viscoelastic stress analysis, Proc. Fourth U. S. Natl. Congr. Appl. Mech., 4, 1075-1085, 1961.

Shen, Z. K., D. D. Jackson, Y. Feng, M. Cline, M. Kim, P. Fang, and Y. Bock, Postseismic Deformation Following the Landers Earthquake, California, 28 June 1992, Bull. Seismol. Soc. Am., 84, 780-791, 1994.

Singh, S. J., Static deformation of a multilayered half-space by interna sources, J. Geophys. Res., 75, 3257-3263, 1970.

Spence, D. A., and D. L. Turcotte, Viscoelastic relaxation of cyclic displacements on the San Andreas fault, Proc. R. Soc. London A, 365, 121-144, 1979.

Thatcher, W., and J. B. Rundle, A viscoelastic coupling model for cyclic deformation due to periodically repeated earthquakes at subduction zones, J. Geophys. Res., 89, 7631-7640, 1984.

Turcotte, D. L., J. Y. Liu, and F. H. Kulhawy, The role of an intracrustal asthenosphere on the behavior of major strike-slip faults, J. Geophys. Res., 89, 5801-5816, 1984.

Yang, M., and N. Toksoz, Timedependent deformation and stress relaxation after strike-slip earthquakes, J. Geophys. Res., 86, 2889$2901,1981$.

J. Fernández, Instituto de Astronomica y Geodesia (CSIU-UCM), Facultad de Ciencias Matematicas, Ciudad Universitaria, 28040 - Madrid, Spain.

J. B. Rundle, Cooperative Institute For Research in Environmental Sciences, University of Colorado, Campus Box 216, Boulder, CO 80309-0216. (e-mail: rundle@hopfield.colorado.edu)

T.-T. Yu, Institute of Earth Sciences, Academia Sinica, P. O. Box 155, Nankang, Taipei, Taiwan. (e-mail: yutt@earth.sinica.edu.tw)

(Received December 31, 1994; revised October 6, 1995; accepted October 9, 1995.) 